\title{
What's in a Name? Large Choroidal Nevus, Small Choroidal Melanoma, or Indeterminate Melanocytic Tumor
}

\author{
Arun D. Singh ${ }^{a}$ Hans E. Grossniklaus ${ }^{b}$ \\ aDepartment of Ophthalmic Oncology, Cleveland Clinic Cole Eye Institute, Cleveland, OH, USA; \\ ${ }^{b}$ Departments of Ophthalmology and Pathology, Emory University School of Medicine, Atlanta, GA, USA
}

\section{Introduction}

Lack of clarity while attempting to differentiate between choroidal nevus and melanoma goes back several decades. What was stated by Gass [1] in 1977 in the 33rd Edward Jackson memorial lecture delivered at the American Academy of Ophthalmology still holds true. Although with recent innovations in imaging we are able to detect subtle changes such as orange pigmentation and subretinal fluid that were barely detectable on clinical examination, the diagnostic dilemma persists $[2,3]$. The issue has become more relevant with the use of commercially available molecular prognostic tests (which have been validated only for survival prognosis) [4], as a surrogate for diagnosis of small choroidal melanomas [5-7]. For the purpose of this commentary, the complex clinical situation could be broken down to certain key components.

\section{Lack of Universal Size Criteria/Definition}

According to the WHO, a choroidal nevus is histologically a benign melanocytic neoplasm with small oval or bland-appearing spindle cells and which is usually $<5$

karger@karger.com

(c) 2021 S. Karger AG, Basel

www.karger.com/oop

Karger! $\mathrm{mm}$ in diameter and $<2 \mathrm{~mm}$ in thickness $[8,9]$. While searching for size criteria for a choroidal nevus, one can explore 2 size-based systems of choroidal melanoma that are widely used in the literature, COMS and AJCC. In the inclusion criteria used for enrollment in the small melanoma arm of COMS, tumors $>1.0 \mathrm{~mm}$ in thickness were categorized as small melanomas [10]. So, a nevus could be presumed to be smaller than small choroidal melanoma (LBD $<5.0 \mathrm{~mm}$ and thickness $<1.0 \mathrm{~mm}$ ) because tumors larger than this were labeled as melanoma (small, medium, or large). No such derivation of choroidal nevus definition is possible from review of the AJCC classification as the T1 melanoma has the height $\leq 3.0 \mathrm{~mm}$ and LBD $\leq 12.0$, as the upper limit of size without limits on minimal thickness or LBD for the T1 stage melanoma [11, 12]. As all choroidal melanomas arise from a single and evolve into clinically detectable tumor (driven by specific mutational events) [12-14], there can only be a statistical probability criterion for any tumor size rather than absolute size cutoffs. Therefore, it is not surprising that there is overlap of size between the nevus and melanoma [15]. Some melanomas that are smaller than a "typical nevus" can metastasize [16]. Other parameters such as the product of 3 linear dimensions [17, 18] and volume [19] are subject to the same unavoidable overlap. 
The lack of a well-defined size-based classification system is the primary reason for inconsistent estimates of risk of malignant growth among studies as they have all used varying inclusion criteria $[20,21]$. Another problem is bias caused by retrospective data collection, except for studies by Gass and the COMS group [22, 23].

\section{Lack of Uniform Terminology}

The commonly used term, such as "suspicious nevus" is rather confusing. If the intent is to state that the lesion may be melanoma, then it would be more accurate to label it as "suspicious for melanoma" rather than "suspicious nevus." Terms such as "benign melanoma," "dormant melanoma," and "simple melanoma" are not supported by our current understanding of the behavior of melanoma and its pathogenesis and so should not be used $[24,25]$.

\section{Secondary Effects on Adjacent Tissues}

The presence of orange pigment and subretinal fluid as markers of acute change favors a diagnosis of melanoma, whereas drusen and intraretinal cystic spaces, being signs of chronicity associated with a long-standing stable lesion, are likely to indicate a benign lesion (such as nevus) [21]. Risk factors are more informative when assessed in combination than when they are considered individually [26, 27]. Even though there is no consensus regarding specific terminology, a few mnemonics have been devised to describe conglomerations of features that assist clinical diagnosis of lesions whose size, appearance, and nomenclature are not well defined! Two of them, DOCTOR GASS [1] and TFSOM $[28,29]$, are well known in the literature. Multivariable scoring systems mitigate to some extent the problem of overlapping dimensions between nevi and melanomas. It is worth emphasizing that "risk features" widely used to differentiate choroidal nevus from melanoma do not carry externally validated probabilities that have been tested on independent datasets.

\section{Intrinsic Features}

Ideally, we should be assessing the intrinsic, rather than extrinsic, features of the tumor. Because of limited ultrasonographic resolution for small tumors and lack of objective interpretation of the findings, ultrasonography in its current form is not reliable [30, 31]. Intrinsic vascular patterns (indocyanine green angiography and optical coherence tomography) also may be biased by subjective interpretation $[32,33]$. It would be ideal if we could biopsy all small tumors, not so much for histopathology or cytology as differentiation between nevus and low-grade spindle melanoma may be difficult on a small sample, but for mutational profiling [34]. The limited available data indicate that the growth "risk factors" such as presence of orange pigment, SRF, and lack of drusen/RPE changes are not statistically significantly associated with prognostic class as identified by gene expression profiling $[5,6]$. It is possible that with improved understanding of the mutational profile of choroidal nevi, particularly identification of discriminating mutations between choroidal nevus and melanoma, the focus will shift toward mutation profiling rather than clinical features [12].

One caveat is that there have been cases of nonmelanocytic tumors that were incorrectly given diagnosis of melanoma on the basis of their molecular profiles, so cytology should not be entirely abandoned [35]. Liquid biopsies using aqueous, vitreous, or blood samples allow detection of diagnostic mutations without the need for tumor biopsy [36, 37].

\section{Contribution of Circular Logic}

Our decision to treat or observe induces bias as to how these tumors are classified. Following discussion of risk features and predictions of growth and if the patients desire to undergo treatment, we are more likely to label such tumors as melanoma. Conversely, if the mutual decision is to initially observe, some may consider the diagnostic label of "choroidal nevus" to be reasonable as it would be inappropriate not to treat melanoma without delay; however, this term exposes the clinician to a risk of litigation for misdiagnosing melanoma as nevus. An alternative name for "borderline" lesions can be "indeterminate melanocytic tumor" (IMT) that highlights the clinical dilemma. Given the underlying lack of conviction of the clinical diagnosis one way or the other (benign or malignant; choroidal nevus or melanoma), the final therapeutic plan implicitly influences the diagnostic label. In other words, the diagnosis may be based upon management rather than management being determined by the diagnosis. An element of circular logic appears to be skewing the reported outcomes after treatment. A study would report falsely low rates of local recurrence and metastasis if it misdiagnosed choroidal nevi as melanomas. 
In this issue, $\mathrm{Al} \mathrm{Harby} \mathrm{et} \mathrm{al.} \mathrm{[38]} \mathrm{report} \mathrm{the} \mathrm{sensitiv-}$ ity and specificity of the MOLES (mushroom shape, orange pigment, large tumor size, enlarging tumor, and subretinal fluid) scoring system in differentiating choroidal melanomas from nevi. They take a different approach, as the risk of growth (surrogate for melanoma) is not being determined, rather growth is incorporated as one of the 5 factors into the classifier. Each of these features is given a score of 0-2 [39]. An important difference between the MOLES and TFSOM is that TFSOM scores each feature in a binary fashion, whereas MOLES also has an intermediate value because it is aimed at nonexperts who may not be sure whether or not a sign is present. Another important difference from related studies is that the included cases were not limited to small tumors. Rather tumors that would be considered medium and even large sized (COMS criteria) were included in the analysis (median basal diameter 4.5 $\mathrm{mm}$ [range, 0.5-28.8] and a median thickness of $0.9 \mathrm{~mm}$ [range, $0-11]$ ).

By computing the sum total of the scores of the 5 indicators, a final classification of "common nevus," "lowrisk nevus," "high-risk nevus," and "probable melanoma" is generated. MOLES fundamentally differs from previous studies as it is not designed to determine whether or not a tumor will grow in the future, rather the purpose of the MOLES scoring system is to provide a framework for community awareness and appropriate referral for treatment. It appears that MOLES and TFSOM are designed for different stages in the care pathway: MOLES for nonspecialists and TFSOM for specialists, the 2 methods are not competing with each other but complementing each other.

The scoring system was compared with experts' diagnosis of melanoma. In a review of 222 melanocytic choroidal tumors, the MOLES scoring system had high sensitivity (100\%) and high specificity (96\%) in diagnosing 81 melanomas and 135 nevi. The MOLES scoring system compares well with experts' diagnosis with discordance observed only in 6 cases $(2.7 \%)$. The question is not whether the experts were correct, but the focus should be whether our current practice patterns are based upon solid scientific evidence. The biology of a tumor is determined by nature, not a committee.
An alternative name for "borderline" lesions can be "IMT." First reported by Butler et al. [40], as "indeterminate pigmented tumor," the term IMT adds transparency to the decision-making process. For the patient, if managed by observation, use of IMT emphasizes uncertainty of the final diagnosis and hence the need for follow-up to monitor for changes in case the lesion is a melanoma or transforms into melanoma [23]. And, if the IMT is treated, the patient has awareness that the lesion may not be metastatic as it may have been a nevus $[23,41]$. Another benefit of the IMT acronym is the implied need for further research. So, if you ask me, what's in a name? The answer is - "everything!"

\section{Conflict of Interest Statement}

Prof. Arun D. Singh and Prof. Grossniklaus are the Editors-inChief of Ocular Oncology and Pathology. Arun D. Singh has reported having relevant financial activities outside the submitted work: Aura Biosciences (stock options), IsoAid LLC (consultancy), Immunocore (consultancy), Isoaid (consultancy), and Eckert and Zeigler (consultancy). Prof. Hans E. Grossniklaus has not reported relevant financial activities.

\section{Funding Sources}

The authors did not receive any funding.

\section{Author Contributions}

Both authors contributed to writing and editing of the manuscript.

\begin{tabular}{|c|c|c|}
\hline References & 1 & $\begin{array}{l}\text { Gass JD. Problems in the differential diagno- } \\
\text { sis of choroidal nevi and malignant melano- } \\
\text { ma. XXXIII Edward Jackson Memorial lec- } \\
\text { ture. Trans Sect Ophthalmol Am Acad Oph- } \\
\text { thalmol Otolaryngol. } 1977 \text { Jan-Feb; 83(1): } \\
\text { 19-48. } \\
\text { Singh AD, Belfort RN, Sayanagi K, Kaiser PK. } \\
\text { Fourier domain optical coherence tomo- } \\
\text { graphic and auto-fluorescence findings in in- } \\
\text { determinate choroidal melanocytic lesions. } \\
\text { Br J Ophthalmol. } 2010 \text { Apr;94(4):474-8. } \\
\text { Dalvin LA, Shields CL, Ancona-Lezama DA, } \\
\text { Yu MD, Di Nicola M, Williams BK Jr, et al. } \\
\text { Combination of multimodal imaging features } \\
\text { predictive of choroidal nevus transformation } \\
\text { into melanoma. Br J Ophthalmol. } 2019 \text { Oct; } \\
\text { 103(10):1441-7. }\end{array}$ \\
\hline
\end{tabular}

Ocul Oncol Pathol 2021;7:235-238 237 
4 Bellerive C, Grossniklaus HE, Singh AD. Prognostication for uveal melanoma: are two tests better than one? Ocul Oncol Pathol. 2017 Nov;3(4):301-3.

5 Nguyen BT, Kim RS, Bretana ME, Kegley E, Schefler AC. Association between traditional clinical high-risk features and gene expression profile classification in uveal melanoma. Graefes Arch Clin Exp Ophthalmol. 2018 Feb; 256(2):421-7.

6 Harbour JW, Paez-Escamilla M, Cai L, Walter SD, Augsburger JJ, Correa ZM. Are risk factors for growth of choroidal nevi associated with malignant transformation? Assessment with a validated genomic biomarker. Am J Ophthalmol. 2019 Jan;197:168-79.

7 Weis E, Roelofs K, Larocque M, Murtha A. Gene expression profiling as an adjunctive measure to guide the management of indeterminate, high-risk choroidal melanocytic lesions: a Pilot Study. Ocul Oncol Pathol. 2019 Feb;5(2):102-9.

8 Shields CL, Furuta M, Mashayekhi A, Berman EL, Zahler JD, Hoberman DM, et al. Clinical spectrum of choroidal nevi based on age at presentation in 3422 consecutive eyes. Ophthalmology. 2008 Mar;115(3):546-e2.

9 Grossniklaus HE, Eberhart CG, Kivela TT. WHO classification of tumours of the eye. 4th ed. Lyon, France: International Agency of Research on Cancer (IARC); 2018.

10 Factors predictive of growth and treatment of small choroidal melanoma: COMS report No. 5. Arch Ophthalmol. 1997;115(12):1537-44.

11 Kujala E, Damato B, Coupland SE, Desjardins L, Bechrakis NE, Grange JD, et al. Staging of ciliary body and choroidal melanomas based on anatomic extent. J Clin Oncol. 2013 Aug 1; 31(22):2825-31.

12 Harbour JW, Chao DL. A molecular revolution in uveal melanoma: implications for patient care and targeted therapy. Ophthalmology. 2014 Jun;121(6):1281-8.

13 Singh N, Singh AD, Hide W. Inferring an evolutionary tree of uveal melanoma from genomic copy number aberrations. Invest Ophthalmol Vis Sci. 2015 Oct;56(7):6801.

14 Field MG, Durante MA, Anbunathan H, Cai LZ, Decatur CL, Bowcock AM, et al. Punctuated evolution of canonical genomic aberrations in uveal melanoma. Nat Commun. 2018 Jan 9;9(1):116.

15 Augsburger JJ, Correa ZM, Trichopoulos N, Shaikh A. Size overlap between benign melanocytic choroidal nevi and choroidal malignant melanomas. Invest Ophthalmol Vis Sci. 2008 Jul;49(7):2823-8.
16 Jouhi S, Jager MJ, de Geus SJR, Desjardins L, Eide NA, Grange JD, et al. The small fatal choroidal melanoma study. A survey by the European ophthalmic oncology group. Am J Ophthalmol. 2019 Jun;202:100-8.

17 Thomas JV, Green WR, Maumenee AE. Small choroidal melanomas. A long-term follow-up study. Arch Ophthalmol. 1979 May;97(5): 861-4.

18 Gass JD. Comparison of uveal melanoma growth rates with mitotic index and mortality. Arch Ophthalmol. 1985 Jul;103(7):924-31.

19 McLean MJ, Foster WD, Zimmerman LE. Prognostic factors in small malignant melanomas of choroid and ciliary body. Arch Ophthalmol. 1977 Jan;95(1):48-58.

20 Singh AD, Mokashi AA, Bena JF, Jacques R, Rundle PA, Rennie IG. Small choroidal melanocytic lesions: features predictive of growth. Ophthalmology. 2006 Jun;113(6):1032-9.

21 Materin M, Singh AD, editors. Benign melanocytic tumors of the uvea. Heidelberg: Springer Nature; 2019.

22 Gass JD. Observation of suspected choroidal and ciliary body melanomas for evidence of growth prior to enucleation. Retina. 1980 Jun; 23(6):523-8.

23 Group C. Factors predictive of growth and treatment of small choroidal melanoma: COMS report No. 5. The Collaborative Ocular Melanoma Study Group. Arch Ophthalmol. 1997 Dec;115(12):1537-44.

24 Hale PN, Allen RA, Straatsma BR. Benign melanomas (nevi) of the choroid and ciliary body. Arch Ophthalmol. 1965 Oct;74(4):532-

25 Naumann G, Yanoff M, Zimmerman LE. Histogenesis of malignant melanomas of the uvea. I. Histopathologic characteristics of nevi of the choroid and ciliary body. Arch Ophthalmol. 1966 Dec;76(6):784-96.

26 Shields CL, Cater J, Shields JA, Singh AD, Santos MC, Carvalho C. Combination of clinical factors predictive of growth of small choroidal melanocytic tumors. Arch Ophthalmol. 2000 Mar;118(3):360-4.

27 Singh AD, Schachat AP, Diener-West M, Reynolds SM. Small choroidal melanoma. Ophthalmology. 2008 Dec;115(12):2319-e3.

28 Shields CL, Shields JA, Kiratli H, De Potter P, Cater JR. Risk factors for growth and metastasis of small choroidal melanocytic lesions. Ophthalmology. 1995 Sep;102(9):1351-61.

29 Shields CL, Furuta M, Berman EL, Zahler JD, Hoberman DM, Dinh DH, et al. Choroidal nevus transformation into melanoma: analysis of 2514 consecutive cases. Arch Ophthalmol. 2009 Aug;127(8):981-7.
30 Fonkeu Y, Singh N, Hayden-Loreck B, Singh AD. Diagnostic A-scan of choroidal melanoma: automated quantification of parameters. Ocul Oncol Pathol. 2019 Aug;5(5):350-7.

31 Singh N, Fonkeu Y, Lorek BH, Singh AD. Diagnostic A-scan of choroidal tumors: comparison of quantified parameters. Ocul Oncol Pathol. 2019;5(5):358-68.

32 Singh AD, Bena JF, Mokashi AA, Jacques R, Rundle PA, Rennie IG. Growth of small tumors. Ophthalmology. 2006 Jun; 113(6): 1061-4.

33 Maloca P, Gyger C, Hasler PW. A pilot study to compartmentalize small melanocytic choroidal tumors and choroidal vessels with speckle-noise free $1050 \mathrm{~nm}$ swept source optical coherence tomography (OCT choroidal "tumoropsy"). Graefes Arch Clin Exp Ophthalmol. 2016 Jun;254(6):1211-9.

34 Singh AD, Zabor EC, Radivoyevitch T. Estimating cured fractions of uveal melanoma. JAMA Ophthalmol. 2021;139(2):174-81.

35 Bellerive C, Binkley E, Singh AD. Class 2 gene expression profile of a hemorrhagic pigment epithelial detachment misdiagnosed as melanoma. Ophthalmol Retina. 2019 May;3(5): 453-5.

36 Wierenga APA, Cao J, Mouthaan $\mathrm{H}$, van Weeghel C, Verdijk RM, van Duinen SG, et al. Aqueous humor biomarkers identify three prognostic groups in uveal melanoma. Invest Ophthalmol Vis Sci. 2019 Nov 1;60(14): 4740-7.

37 Jin E, Burnier JV. Liquid biopsy in uveal melanoma: are we there yet? Ocul Oncol Pathol. 2021;7:1-16.

38 Al Harby L, Sagoo MS, O’Day R, Hay G, Arora AK, Keane PA, et al. Distinguishing choroidal nevi from melanomas using the MOLES algorithm: evaluation in an ocular nevus clinic. Ocul Oncol Pathol. 2021. https://doi. org/10.1159/000511363.

39 Roelofs KA, O’Day R, Harby LA, Arora AK, Cohen VML, Sagoo MS, et al. The MOLES system for planning management of melanocytic choroidal tumors: is it safe? Cancers. 2020 May 21;12(5):1311.

40 Butler P, Char DH, Zarbin M, Kroll S. Natural history of indeterminate pigmented choroidal tumors. Ophthalmology. 1994 Apr;101(4): 710-7; discussion 17.

41 Yupari RJ, Bena J, Wilkinson A, Suh J, Singh A. Small choroidal melanoma: outcomes following apical height dose brachytherapy. Br J Ophthalmol. 2020 Sep 2. 